Check for updates

Cite this: RSC Adv., 2018, 8, 35353

Received 12th August 2018

Accepted 28th September 2018

DOI: $10.1039 / \mathrm{c} 8 \mathrm{ra06765a}$

rsc.li/rsc-advances

\section{Cost effective synthesis of p-type Zn-doped MgAgSb by planetary ball-milling with enhanced thermoelectric properties}

\author{
Yanyan Zheng, ${ }^{a}$ Chengyan Liu, ${ }^{a}$ Lei Miao, (D) *a Hong Lin, (D) ${ }^{b}$ Jie Gao, ${ }^{a}$ \\ Xiaoyang Wang, ${ }^{a}$ Junliang Chen, ${ }^{a}$ Shaohai $\mathrm{Wu}^{a}{ }^{a}$ Xin $\mathrm{Li}^{\mathrm{a}}$ and Huanfu Cai ${ }^{\mathrm{C}}$
}

\begin{abstract}
As promising candidates for the progress of low-temperature thermoelectric devices, MgAgSb-based thermoelectric materials have drawn a great deal of attention. However, due to complicated phase changes, high content of impurities and high volatilization of $\mathrm{Mg}$, it is difficult to synthesize pure phase MgAgSb-based thermoelectric materials via conventional methods. Here, MgAgSb alloy was successfully synthesized by a combination of common planetary ball milling and spark plasma sintering. Furthermore, the introduction of $\mathrm{Zn}$ improved the purity of alloys, leading to optimization of the electrical transport properties. As a result, the power factor was improved from $1087 \mu \mathrm{W} \mathrm{m}{ }^{-1} \mathrm{~K}^{-2}$ for $\mathrm{MgAg}_{0.9} \mathrm{Sb}_{0.95}$ to 1394 $\mu \mathrm{W} \mathrm{m}{ }^{-1} \mathrm{~K}^{-2}$ for $\mathrm{Mg}_{0.97} \mathrm{Zn}_{0.03} \mathrm{Ag}_{0.9} \mathrm{Sb}_{0.95}$ at $473 \mathrm{~K}$, and the $Z T$ reached $\sim 0.7$ at $473 \mathrm{~K}$. These results suggest that MgAgSb-based thermoelectric materials have a good thermoelectric application potential and this study can be used as guidance for the synthesis and performance improvement of other thermoelectric materials. Our synthesis route sets forth a new avenue for accelerating commercial applications of MgAgSb-based thermoelectric power generation or refrigeration.
\end{abstract}

\section{Introduction}

Thermoelectric (TE) materials can directly convert thermal energy into electrical energy and have been widely used in power generation and cooling devices in the past decades. ${ }^{1}$ The energy conversion efficiency of TE materials is mainly determined by the dimensionless figure of merit, $Z T=S^{2} \sigma T / \kappa_{\text {tot }}$, where $S, \sigma, T$ and $\kappa_{\text {tot }}$ are the Seebeck coefficient, the electrical conductivity, the absolute temperature and the thermal conductivity, respectively. ${ }^{2,3}$ Hence, in order to reach high $Z T$, it is imperative to minimize heat transport and simultaneously maintain good electrical properties. ${ }^{4}$ Two state-of-the-art methods for enhancing $Z T$ of existing materials are optimizing the power factor (PF) and reducing the lattice thermal conductivity. For the former, it can be realized through band engineering, ${ }^{5}$ carrier concentration optimization, ${ }^{6,7}$ promotion of carrier mobility ${ }^{\mathbf{8}, 9}$ and searching for materials with high PF. ${ }^{\mathbf{1 0}}$ For the latter, controlling the nano-microstructures ${ }^{11}$ and developing materials with intrinsically low thermal conductivity

${ }^{a}$ Guangxi Key Laboratory of Information Materials, Guangxi Collaborative Innovation Center of Structure and Property for New Energy and Materials, School of Material Science and Engineering, Guilin University of Electronic Technology, Guilin, 541004, P. R. China. E-mail: miaolei@guet.edu.cn

${ }^{b}$ State Key Laboratory of New Ceramic and Fine Processing, School of Materials Science and Engineering, Tsinghua University, Beijing, 100084, P. R. China

${ }^{c}$ Institute of Information Engineering, Guangdong University of Finance, Guangzhou, 510520, P. R. China have proven to be effective ways for enhancing $Z T \cdot{ }^{\mathbf{1 2 - 1 4}}$ Optimization of carrier concentration and microscopic control of nanostructures are the main methods to improve TE performance. Several TE materials with high $Z T$ are being explored widely, including SnSe, ${ }^{15}$ GeTe, ${ }^{16} \mathrm{Cu}_{2} \mathrm{Se}^{17}$ and $\mathrm{Bi}_{2} \mathrm{Te}_{3} \cdot{ }^{18}$ Commercially used TE materials for solid state refrigeration are mainly $\mathrm{Bi}_{2} \mathrm{Te}_{3}$-based alloys near room temperature. ${ }^{\mathbf{1 9 2 0}}$ However, due to the lack of elemental content, toxicity and poor mechanical stability, commercial applications of the above materials are severely limited. Therefore, it is crucial to develop TE materials with more favorable characteristics.

Recently, $\mathrm{Mg}_{3} \mathrm{Sb}_{2}$ (ref. 21) and Half-Heusler ${ }^{22-29}$ compounds have caused significant concern. The common problem is that these compounds are used only at moderate and high temperature ranges. MgAgSb materials have been extensively studied due to their excellent TE performance including intrinsic low thermal conductivity, rich elemental content, good mechanical stability and thermal stability at room temperature. ${ }^{30}$ Tan et al. has proposed that high $Z T$ can be achieved by band engineering to improve the TE performance of MgAgSb via $\mathrm{Zn}$ and $\mathrm{Pd}$ doping. ${ }^{31}$ Although the MgAgSb-based TE materials with high performance can be used at near room temperature, the synthesis of pure phase MgAgSb is still an issue. There are three different crystal structures of MgAgSb: (1) a tetragonal $\alpha$-phase with a space group of $I \overline{4} c 2$ at low temperature (room-590 K), (2) a $\mathrm{Cu}_{2} \mathrm{Sb}$-related $\beta$-phase with a space group of $P 4 / \mathrm{nmm}$ at intermediate temperature (590-630 K), and (3) a Half-Heusler $\gamma$ phase with a space group of $F \overline{4} 3 m$ at high temperature (630-700 
K). ${ }^{32}$ Complicated phase changes and high content of $\mathrm{Ag}_{3} \mathrm{Sb}$ were generated easily while preparing MgAgSb materials. At the same time, magnesium, the major component of $\mathrm{MgAgSb}$, is active and easily oxidized. Therefore, the air-free environment is essential for the synthesis of MgAgSb. Besides, magnesium can react with the quartz glass tube, making synthesis conditions challenging. Based on the above problems, two synthetic methods for the preparation of $\mathrm{MgAgSb}$ materials have been developed: (1) the combination of two-step mechanical alloying by high energy ball-milling and low temperature hot pressing, ${ }^{33}$ and (2) the combination of high temperature melting, spark plasma sintering and heat treating at high temperature. ${ }^{34}$ In addition, due to the high cost of high-energy ball milling and the complexity of the high-temperature sintering synthesis process, there are some difficulties for the synthesis of $\mathrm{MgAgSb}$ based TE materials. However, the ordinary ball-milling has lots of advantages, such as low center of gravity, stable performance, easy operation, safety, reliability, and low noise and loss levels.

In this study, the combination of adjusting the element ratio, ball milling time of ordinary planetary ball milling and spark plasma sintering has been adapted to prepare MgAgSb successfully. We compared our work with other groups' experimental processes and data. As shown in Table 1, the advantages and some novelties of our materials compared with the commercial $\mathrm{Bi}_{2} \mathrm{Te}_{3}$ materials are: (1) MgAgSb materials are cheaper, less toxic, and exhibit richer elemental content, better mechanical stability, thermal stability and lower thermal conductivity at room temperature. (2) At present, this synthesis method of combining a common planetary ball milling and spark plasma sintering has not been reported for MgAgSb materials. Our synthesis method effectively avoids the reaction of $\mathrm{Mg}$ with the quartz tube and has the advantages of being easy, fast and highly efficient. This study provides guidance for the synthesis and performance improvement of other thermoelectric materials. In addition, $\mathrm{Zn}$ doping has not been reported yet for MgAgSb materials. After doping with $\mathrm{Zn}$, the improvement of total TE performances has been achieved with maximum $Z T$ values of 0.7 at $473 \mathrm{~K}$. Our study proposes that MgAgSb-based materials are promising candidates for the development of low-temperature TE devices, which are beneficial for applications in low temperature power generation and cooling systems with improved energy conversion efficiency.

\section{Materials and methods}

\section{Synthesis process}

The samples were fabricated by combining the ordinary planetary ball-milling (WXQM-1L) and spark plasma sintering (SPS, LABOX-325, SINTER LAND INC.) processes. Mg (99.5\%, Aladdin), Ag (99.9\%, Macklin), Sb (99.5\%, Aladdin), and Zn (99.99\%, Aladdin) were weighed with the nominal composition $\mathrm{Mg}_{1-x} \mathrm{Zn}_{x} \mathrm{Ag}_{0.9} \mathrm{Sb}_{0.95}(x=0 \%, 2 \%, 3 \%, 4 \%$ and $5 \%)$ and then loaded into the stainless steel jar in a glove-box under argon atmosphere. These powders were subjected to ordinary planetary ball-milling at $600 \mathrm{rpm}$ for $18 \mathrm{~h}$ under argon atmosphere. Then they were densified in a graphite die of $\Phi 15 \mathrm{~mm}$ and sintered by SPS at $573 \mathrm{~K}$ for $10 \mathrm{~min}$ under an axial compressive stress of $50 \mathrm{MPa}$ in vacuum. The relative densities were approximately $94 \%$ of the theoretical values. $Z T$ measurement uncertainty: the uncertainties of the electrical resistivity and Seebeck coefficient are 3\%; the uncertainty for the total thermal conductivity is about $12 \%$. The uncertainty for the final $Z T$ is about $20 \%$.

\section{Characterization}

The powder diffractometer (D8 Advance, Bruker) was used to observe X-ray diffraction (XRD) patterns. The morphology observation was performed by field-emission scanning-electron microscopy (FESEM, Hitachi S-4800, Japan). The electrical resistivity and Seebeck coefficient were measured simultaneously by the dynamic direct current (DC) method (CTA-3, Cryall) with temperature gradients of $30 \mathrm{~K}, 40 \mathrm{~K}$, and $50 \mathrm{~K}$ in a low pressure argon (99.999\%) atmosphere. The thermal conductivity $\left(\kappa_{\text {tot }}\right)$ was calculated using the equation $\kappa_{\text {tot }}=D \rho C_{\mathrm{p}}$, where $D, \rho$ and $C_{\mathrm{p}}$ are the thermal diffusivity, the measured density, and the specific heat, respectively. The laser flash thermal analyzer (EM-500, TA) was used to measure the thermal diffusivity coefficient. Density was measured multiple times using the Archimedes method. The differential scanning calorimetry (DSC-404F3, NETZSCH) was used to measure the specific heat. The Hall coefficient $\left(R_{\mathrm{H}}\right)$ at room temperature was measured by the Physical Properties Measurement System (PPMS, Quantum Design, Inc.). The Hall carrier concentration $(n)$ and mobility $(\mu)$ were calculated using equations: $R_{\mathrm{H}}=1 / n \mathrm{e}$ and $\sigma=n e \mu$, respectively.

Table 1 Comparison of the figures of merit of commercial and similar doped MgAgSb materials ${ }^{a}$

\begin{tabular}{llll}
\hline Materials & Carrier type & $Z T$ & Method \\
\hline $\mathrm{BiSbTe}$ & $\mathrm{p}$ & $1.4(373 \mathrm{~K})$ & BM-HP \\
$\mathrm{Bi}_{0.4} \mathrm{Sb}_{1.6} \mathrm{Te}_{3}$ & $\mathrm{p}$ & $1.1(673 \mathrm{~K})$ & Melt-SPS \\
$\mathrm{Bi}_{0.5} \mathrm{Sb}_{1.5} \mathrm{Te}_{3}$ & $\mathrm{p}$ & $1.3(10 \mathrm{~K})$ & ZM-HP \\
$\alpha^{-\mathrm{MgAgSb}}$ & $\mathrm{p}$ & $0.56(433 \mathrm{~K})$ & MQG-HP-Anneal \\
$\mathrm{MgAg}_{0.965} \mathrm{Ni}_{0.005} \mathrm{Sb}_{0.99}$ & $\mathrm{p}$ & $1.4(450 \mathrm{~K})$ & TwO-step BM-HP-Anneal \\
$\mathrm{MgAgSb}_{0.99} \mathrm{In}_{0.01}$ & $\mathrm{p}$ & $1.1(525 \mathrm{~K})$ & MQG-SPS-Anneal \\
$\mathrm{MgAg}_{0.97} \mathrm{Sb}_{0.99}$ & $\mathrm{p}$ & $0.85(375 \mathrm{~K})$ & MQG-SPS-Anneal-Quench \\
$\mathrm{Mg}_{0.97} \mathrm{Zn}_{0.03} \mathrm{Ag}_{0.9} \mathrm{Sb}_{0.95}$ & $\mathrm{p}$ & $0.7(473 \mathrm{~K})$ & PBM-SPS \\
${ }^{a} \mathrm{BM}=$ high energy ball milling; HP & $=$ hot-pressing; SPS = spark plasma sintering; ZM = zone melting; MQG = melting + quenching + grinding; \\
$\mathrm{PBM}=$ planetary ball milling. & &
\end{tabular}



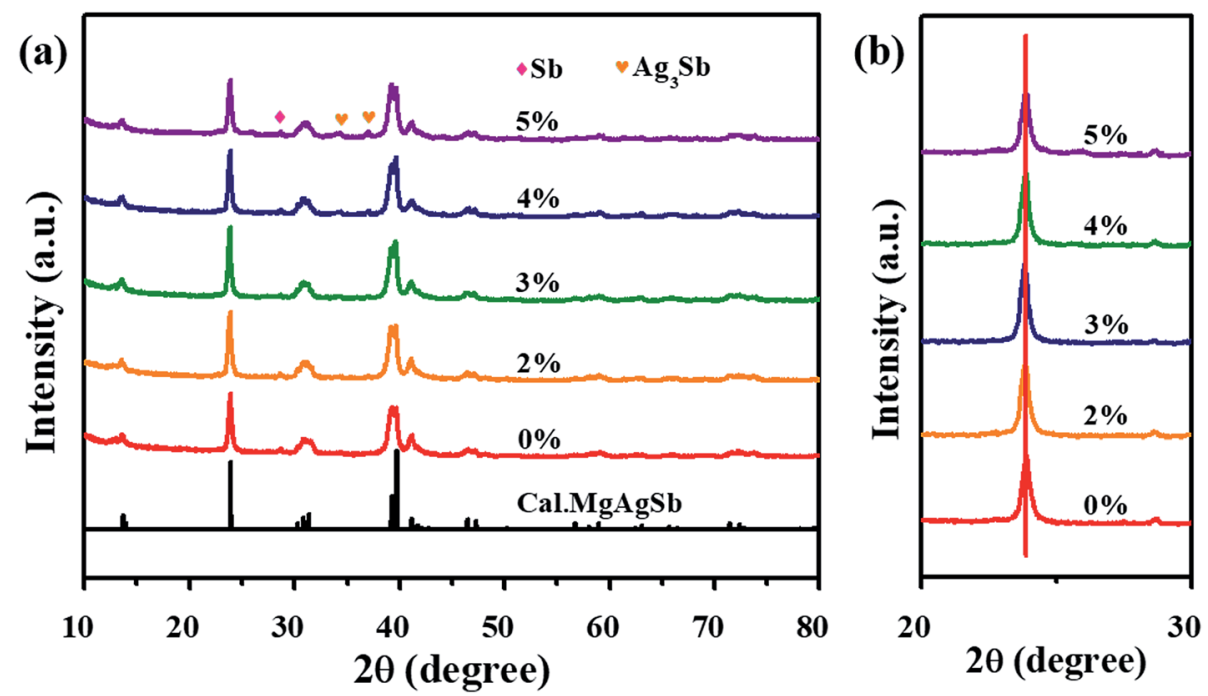

Fig. 1 XRD patterns of $\mathrm{Mg}_{1-x} \mathrm{Zn}_{x} \mathrm{Ag}_{0.9} \mathrm{Sb}_{0.95}(x=0 \%, 2 \%, 3 \%, 4 \%$ and $5 \%)$ samples. The value we calculated based on refined parameters is shown at the bottom.
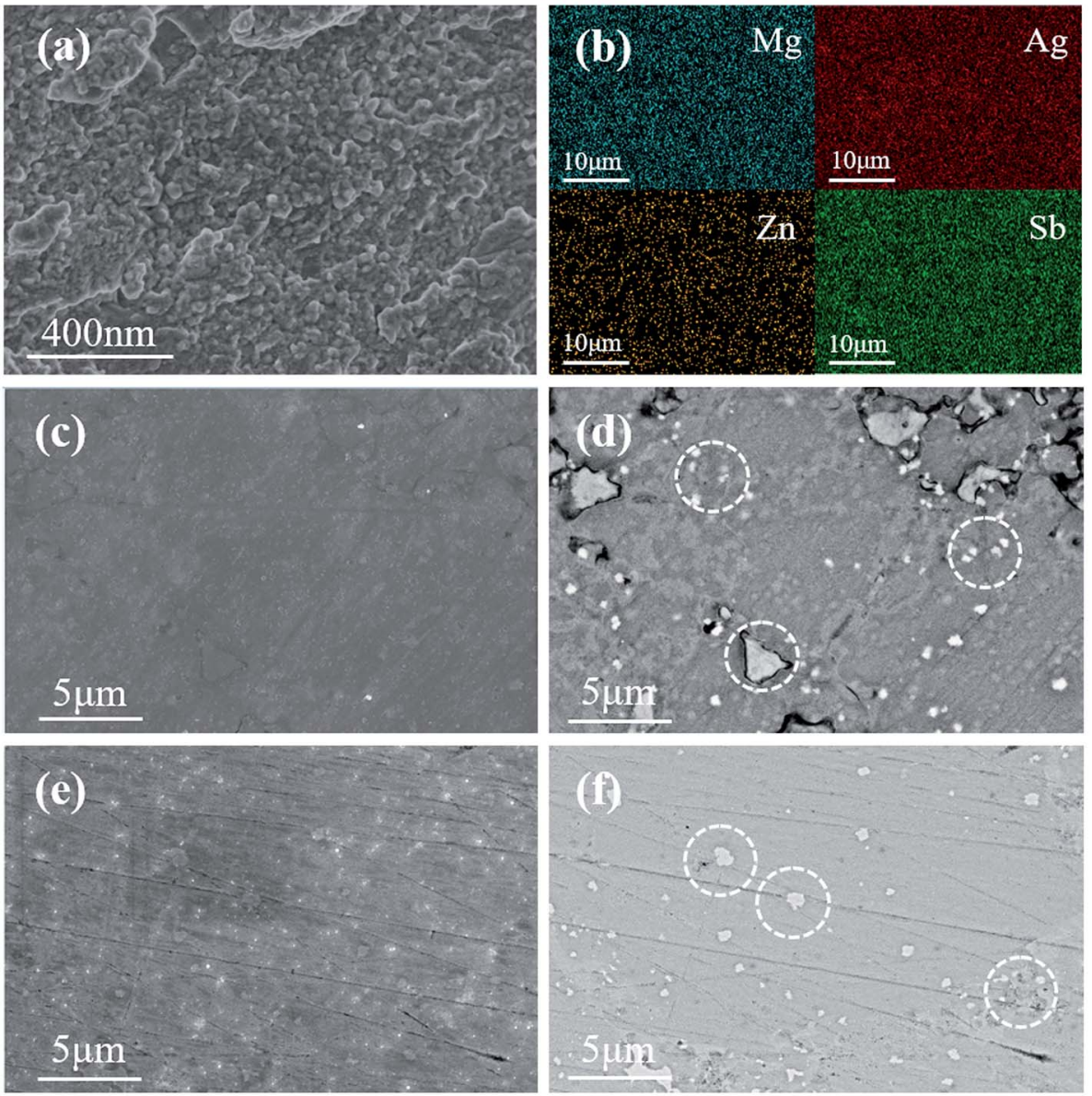

Fig. 2 SEM images of $\mathrm{Mg}_{1-x} \mathrm{Zn}_{x} \mathrm{Ag}_{0.9} \mathrm{Sb}_{0.95}\left(x=0 \%\right.$ and 3\%). (a) Freshly broken surface of disc sample $\mathrm{Mg}_{0.97} \mathrm{Zn}_{0.03} \mathrm{Ag}_{0.9} \mathrm{Sb}_{0.95}$; (b) elemental distribution of $\mathrm{Mg}_{0.97} \mathrm{Zn}_{0.03} \mathrm{Ag}_{0.9} \mathrm{Sb}_{0.95}$ determined by EDX; ( $\mathrm{c}$ and d) polished surface of $\mathrm{MgAg}_{0.9} \mathrm{Sb}_{0.95}$ by secondary electron and by blackscattering electron imaging, respectively; (e and f) polished surface of $\mathrm{Mg}_{0.97} \mathrm{Zn}_{0.03} \mathrm{Ag}_{0.9} \mathrm{Sb}_{0.95}$ by secondary electron and by black-scattering electron imaging, respectively. 

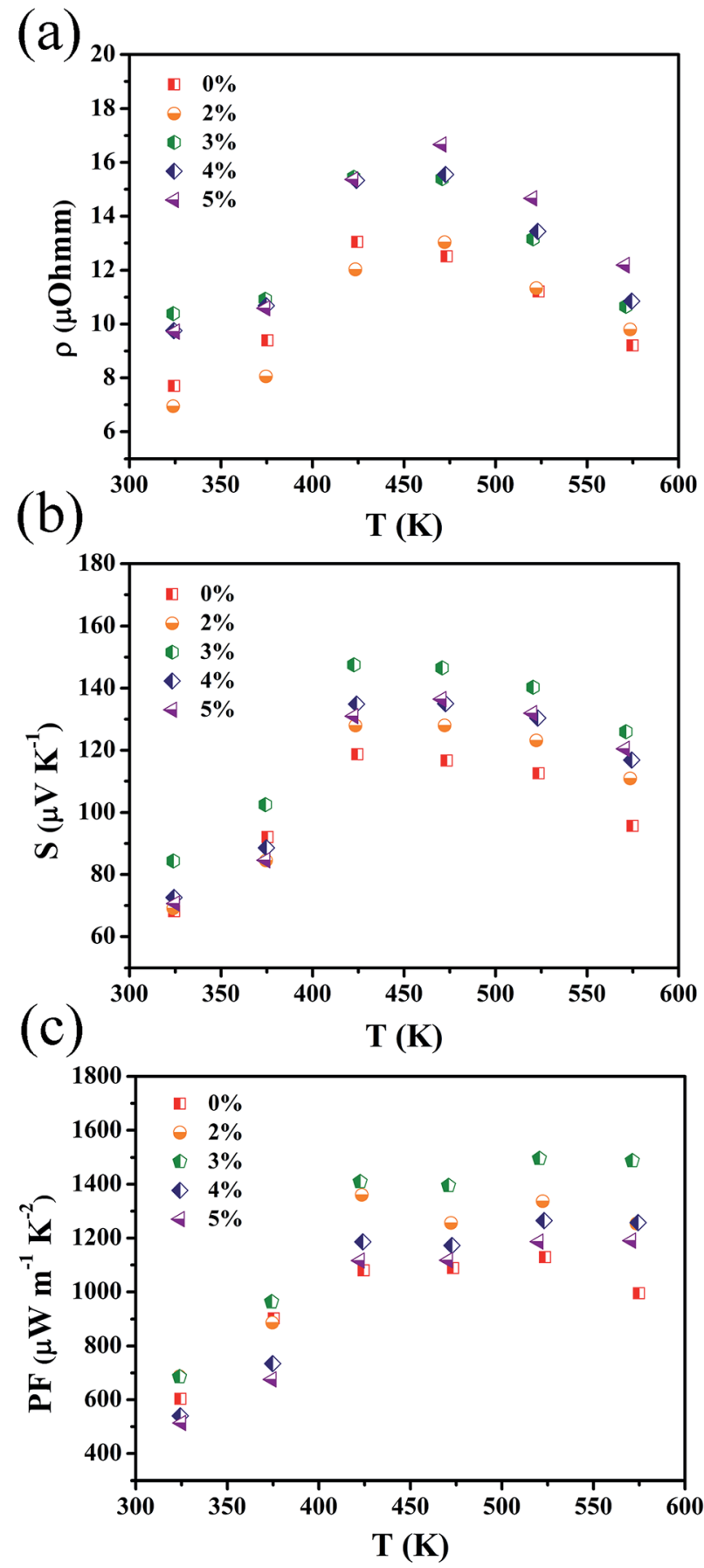

Fig. 3 Temperature dependencies of (a) electrical resistivity; (b) Seebeck coefficient and (c) power factor of $\mathrm{Mg}_{1-x} \mathrm{Zn}_{x} \mathrm{Ag}_{0.9} \mathrm{Sb}_{0.95}(x=0-$ $5 \%)$, respectively.

\section{Results and discussion}

Fig. 1(a) displays the XRD patterns of $\mathrm{Mg}_{1-x} \mathrm{Zn}_{x} \mathrm{Ag}_{0.9} \mathrm{Sb}_{0.95}(0 \% \leq$ $x \leq 5 \%$ ) samples. The diffraction peaks of the samples are wellmatched with the calculated results for MgAgSb with $I \overline{4} c 2$ space group. From the XRD patterns, the impurity of $\mathrm{Sb}$ is more obvious without $\mathrm{Zn}$ doping and there are co-existing phases consisting of the main phase $\mathrm{MgAgSb}$, and a few impurity phases of $\mathrm{Sb}$ and $\mathrm{Ag}_{3} \mathrm{Sb}$ without doping. The contents of impurity reduced with the increasing doped amount of $\mathrm{Zn}$ until the $\mathrm{Zn}$ content exceeded $3 \%$. There is only a trace amount of impurity phase of $\mathrm{Sb}$, and $\mathrm{Ag}_{3} \mathrm{Sb}$ is occasionally observed when $x$ $=3 \%$. Afterwards, metallic $\mathrm{Sb}$ and $\mathrm{Ag}_{3} \mathrm{Sb}$ exist in the main phase of MgAgSb when $x>3 \%$. Therefore, it could be inferred that $\mathrm{Zn}$ doping can improve the purity and crystallinity of MgAgSb, enhancing the electrical properties as shown later.

Looking at the main peaks in the regions of $20 \sim 30^{\circ}$, as shown in Fig. 1(b), one can see that these peaks do not shift toward low or high diffraction angles with the increase in $\mathrm{Zn}$ content. This suggests that $\mathrm{Zn}$ doping has less effect on the lattice structure due to the closer ionic radius between $\mathrm{Mg}(0.66$ $\AA)$ and $\mathrm{Zn}(0.68 \AA)$ than $\mathrm{Sb}(0.76 \AA)$ and $\mathrm{Ag}(1.15 \AA) .{ }^{39}$ Thus, it is easier to replace $\mathrm{Zn}$ with $\mathrm{Mg}$ in the lattice.

Fig. 2 shows the SEM images of $\mathrm{Mg}_{1-x} \mathrm{Zn}_{x} \mathrm{Ag}_{0.9} \mathrm{Sb}_{0.95}(x=0 \%$ and $3 \%$ ). The freshly broken surface of $\mathrm{Mg}_{0.97} \mathrm{Zn}_{0.03} \mathrm{Ag}_{0.9} \mathrm{Sb}_{0.95}$ sample was shown in Fig. 2(a), the grain size is from $50 \mathrm{~nm}$ to $200 \mathrm{~nm}$. As shown in Fig. 2(b), energy dispersive X-ray spectroscopy (EDX) images show that all the elements are homogeneously distributed in the sample. Due to the low resolution of EDX, the medium magnification TEM images are shown in Fig. 2(c) and (d). There are a few impurities in $\mathrm{MgAg}_{0.9} \mathrm{Sb}_{0.95}$ and the grain size of impurities is from $200 \mathrm{~nm}$ to $3 \mu \mathrm{m}$. Fig. 2(e) and (f) show the polished surface of $\mathrm{Mg}_{0.97} \mathrm{Zn}_{0.03} \mathrm{Ag}_{0.9} \mathrm{Sb}_{0.95}$, indicating that the impurities are reduced by $3 \% \mathrm{Zn}$ doping and the grain size of impurities were decreased to be varying from $100 \mathrm{~nm}$ to $600 \mathrm{~nm}$. It can be inferred that $\mathrm{Zn}$ could combine with $\mathrm{Sb}$ and $\mathrm{Ag}_{3} \mathrm{Sb}$ to form $\mathrm{ZnAgSb}$ to reduce the concentration of impurities ${ }^{\mathbf{4 0}}$ which are easily formed in the absence of $\mathrm{Zn}$ doping.

Fig. 3 shows the temperature dependence of the electrical properties of $\mathrm{Mg}_{1-x} \mathrm{Zn}_{x} \mathrm{Ag}_{0.9} \mathrm{Sb}_{0.95}(x=0-5 \%)$ samples. When the measured temperature increased from 323 to $573 \mathrm{~K}$, the electrical resistivity first increased and then decreased significantly. The highest electrical resistivity is reached at $423 \sim 473$ $\mathrm{K}$, which is shown in Fig. 3(a). The electrical resistivity of all samples increases with an increase in Zn content. Typically, as the carrier concentration gradually decreases, as shown in Fig. 4(a), the electrical resistivity at $473 \mathrm{~K}$ increases from $1.25 \times$ $10^{-5} \Omega \mathrm{m}$ for $\mathrm{MgAg}_{0.9} \mathrm{Sb}_{0.95}$ to $1.54 \times 10^{-5} \Omega \mathrm{m}$ for $\mathrm{Mg}_{0.97^{-}}$ $\mathrm{Zn}_{0.03} \mathrm{Ag}_{0.9} \mathrm{Sb}_{0.95}$. The higher electrical resistivity below $450 \mathrm{~K}$ for $3 \% \mathrm{Zn}$ doping and above $450 \mathrm{~K}$ for $5 \% \mathrm{Zn}$ doping is due to the appearance of $\mathrm{Sb}$ and $\mathrm{Ag}_{3} \mathrm{Sb}$ impurities when the $\mathrm{Zn}$ content exceeds $3 \%$, which leads to the low resistivity. In addition, the decrease of electrical resistivities above $450 \mathrm{~K}$ could be attributed to the bipolar effect. ${ }^{\mathbf{4 1}}$

The temperature dependence of the Seebeck coefficient for all the $\mathrm{Zn}$ doped samples is shown in Fig. 3(b), which indicates that all the samples are p-type semiconductors. The Seebeck coefficient of $\mathrm{Mg}_{1-x} \mathrm{Zn}_{x} \mathrm{Ag}_{0.9} \mathrm{Sb}_{0.95}$ samples increases with increasing Zn content $(x \leq 3 \%)$ and peak sat $423 \mathrm{~K}$. This observation can be ascribed to the typical characteristic of bipolar diffusion effect caused by a narrow band gap for MgAgSb-based materials. ${ }^{34}$ The Seebeck coefficient for sample $\mathrm{MgAg}_{0.9} \mathrm{Sb}_{0.95}$ at $423 \mathrm{~K}$ is $118 \mu \mathrm{V}$ $\mathrm{K}^{-1}$, which increases to $148 \mu \mathrm{V} \mathrm{K}{ }^{-1}$ for $\mathrm{Mg}_{0.97} \mathrm{Zn}_{0.03} \mathrm{Ag}_{0.9} \mathrm{Sb}_{0.95}$. The significantly enhanced Seebeck coefficient can be attributed to the reduced carrier concentration caused by $\mathrm{Zn}$ doping. 

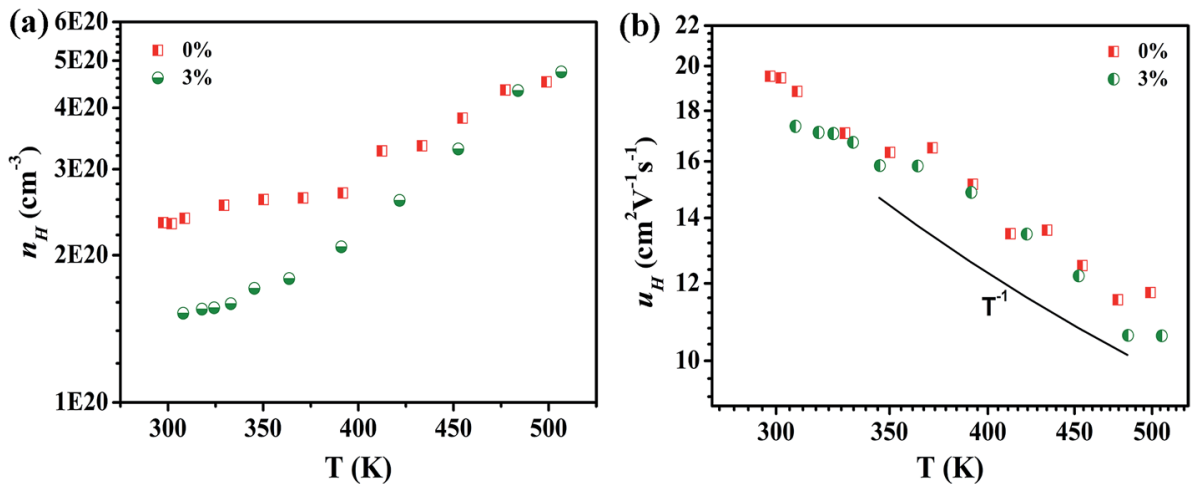

Fig. 4 Temperature dependencies of (a) Hall carrier concentration and (b) Hall mobility for $\mathrm{Mg}_{1-x} \mathrm{Zn}_{x} \mathrm{Ag}_{0.9} \mathrm{Sb}_{0.95}(x=0 \%$ and $3 \%$ ), respectively.

The values of the power factor for all Zn doped samples are obtained as shown in Fig. 3(c). With increasing Zn doped content from $x=0 \%$ to $5 \%$, power factor values monotonically increase from $323 \mathrm{~K}$ to $523 \mathrm{~K}$. PF values for $\mathrm{Zn}$ doped $\mathrm{Mg}_{1-x}$ $\mathrm{Zn}_{x} \mathrm{Ag}_{0.9} \mathrm{Sb}_{0.95}(x=2-3 \%)$ samples are significantly higher than that of the $\mathrm{MgAg}_{0.9} \mathrm{Sb}_{0.95}$ sample and the peak value reaches up to $1500 \mu \mathrm{W} \mathrm{m}{ }^{-1} \mathrm{~K}^{-2}$ for $\mathrm{Mg}_{0.97} \mathrm{Zn}_{0.03} \mathrm{Ag}_{0.9} \mathrm{Sb}_{0.95}$ at $523 \mathrm{~K}$.

Fig. 4 shows the temperature dependencies of Hall carrier concentration and Hall mobility of $\mathrm{Mg}_{1-x} \mathrm{Zn}_{x} \mathrm{Ag}_{0.9} \mathrm{Sb}_{0.95}(x=0 \%$ and $3 \%$ ) samples. The Hall carrier concentration increases with elevating temperature as shown in Fig. 4(a). Notably, the carrier concentration rapidly decreases from $2.32 \times 10^{20}$ to $1.55 \times 10^{20}$ $\mathrm{cm}^{-3}$ at $300 \mathrm{~K}$ due to the decrease in impurities with $\mathrm{Zn}$ doping. As the major component of MgAgSb, $\mathrm{Mg}$ is easily volatilized to form the $\mathrm{Mg}$ vacancy during the synthesis processes, which leads to the damage of the materials. Owing to the higher stability of $\mathrm{Zn}$, the volatilization is suppressed with $\mathrm{Zn}$ doping, contributing to the reduction of the vacancy. The results show that as the $\mathrm{Zn}$ content increases, the carrier concentration is significantly reduced. In addition, $\mathrm{Ag}_{3} \mathrm{Sb}$ is a metal and can reduce the Seebeck coefficient by increasing the carrier concentration. Therefore, it can be inferred that $\mathrm{Zn}$ doping improves the purity of MgAgSb, giving rise to its improved electrical properties.

We can see the same trend in Hall mobility of $\mathrm{MgAg}_{0.9} \mathrm{Sb}_{0.95}$ and $\mathrm{Mg}_{0.97} \mathrm{Zn}_{0.03} \mathrm{Ag}_{0.9} \mathrm{Sb}_{0.95}$ in Fig. 4(b). The Hall mobility at room temperature reaches $20 \mathrm{~cm}^{2} \mathrm{~V}^{-1} \mathrm{~s}^{-1}$. The effective concentration of impurities, the carrier concentration and some other material-specific parameters are vital for strengthening the ionized impurity scattering. The carrier relaxation time of ionized impurity scattering under the Born approximation and a coulombic potential screening effect is expressed as: ${ }^{42}$

$$
\tau_{I}=\frac{K^{2}\left(2 m_{d}^{*}\right)^{1 / 2} \varepsilon^{3 / 2}}{\pi e^{4} N_{\mathrm{I}}}\left[\ln (1+b)-\frac{b}{1+b}\right]^{-1} b=\frac{2 K m_{d}^{*} k_{\mathrm{B}} T \varepsilon}{\pi \hbar^{2} e^{2} n^{*}},
$$

where $e$ is the elementary charge, $N_{\mathrm{I}}$ is the effective impurity density, $k_{\mathrm{B}}$ is the Boltzmann constant, and $\hbar$ is the reduced Planck constant. $n^{*}$ is related to the carrier concentration $n$ and the charge compensation (when both acceptors and donors are present), and equal to $n$ if a single type of impurity is present (such as the donors in an n-type semiconductor). It is evident that the carrier screening effect (proportional to $K$ ) and the charge compensation (b) both influence $\tau_{\mathrm{I}}$ significantly. The Hall mobility dependence of temperature $\left(\mu_{\mathrm{H}} v s . T^{-1}\right)$ confirms that all samples exhibit a carrier transport mechanism dominated by ionized impurity scattering. ${ }^{42,43}$

Fig. 5 shows the thermal transport properties of $\mathrm{Mg}_{1-x} \mathrm{Zn}_{x^{-}}$ $\mathrm{Ag}_{0.9} \mathrm{Sb}_{0.95}(x=0-5 \%)$ samples. Diffusivity coefficients of all samples are plotted in Fig. 5(a). The results show that the diffusivity coefficients of all samples first decrease to the minimum at around $423 \sim 473 \mathrm{~K}$ and then increase with rising temperature. With the increase in Zn content, diffusivity coefficients gradually decrease and then increase. When the content of $\mathrm{Zn}$ is $3 \%$, diffusivity coefficient is up to the value of $0.58 \mathrm{~mm}^{2}$ $\mathrm{s}^{-1}$ at $473 \mathrm{~K}$.

Fig. 5(b) shows the total thermal conductivity $\kappa_{t o t}$ of all samples. The thermal conductivity $\left(\kappa_{\text {tot }}\right)$ is calculated using the equation $\kappa_{\text {tot }}=D \rho C_{\mathrm{p}}$. It is clear that increasing the content of $\mathrm{Zn}$ from $x=0 \%$ to $x=3 \%$ gradually decreases the $\kappa_{\text {tot }}$ value within the entire temperature measurement range. $T$ he $\mathrm{Mg}_{0.97} \mathrm{Zn}_{0.03^{-}}$ $\mathrm{Ag}_{0.9} \mathrm{Sb}_{0.95}$ has a lower $\kappa_{\text {tot }}$ of $1.09 \mathrm{~W} \mathrm{~m}^{-1} \mathrm{~K}^{-1}$ than $\kappa_{\text {tot }}$ of other samples at $473 \mathrm{~K}$. This may be ascribed to the strong impurity ion scattering and the grain uniformity in the range of 50$200 \mathrm{~nm} .^{33}$ Ionized impurity scattering could play an important role in the carrier transport $(T>300 \mathrm{~K})$ since almost all of the thermoelectric materials are heavily doped semiconductors. The charged impurities not only filter out low energy carriers but also enhance the phonon scattering. It could be inferred that a simultaneous reduction in thermal conductivity can be achieved. ${ }^{44}$ In addition, ball-milling is an effective top-down industrial approach to obtain fine particles and large quantities of nanoparticles. ${ }^{45}$ All of the grain boundaries, nanointerfaces between nanograins and nanoprecipitates affect the transport of electrons and phonons. ${ }^{46}$ The combination of ionized impurity scattering and the grain boundaries scattering drastically suppresses thermal conductivity. With the increase in $\mathrm{Zn}$ content, the total thermal conductivity gradually increases, which may be due to the presence of $\mathrm{Sb}$ and $\mathrm{Ag}_{3} \mathrm{Sb}$ impurities as shown in Fig. 1.

Fig. 5(c) shows the values of $Z T$ by combining the corresponding results of the electrical and thermal properties. $Z T$ values appear to increase first and then decrease at the recorded temperature. The highest $Z T$ value of 0.7 at $473 \mathrm{~K}$ is achieved for $\mathrm{Mg}_{0.97} \mathrm{Zn}_{0.03} \mathrm{Ag}_{0.9} \mathrm{Sb}_{0.95}$, and then it decreases above $473 \mathrm{~K}$. This 


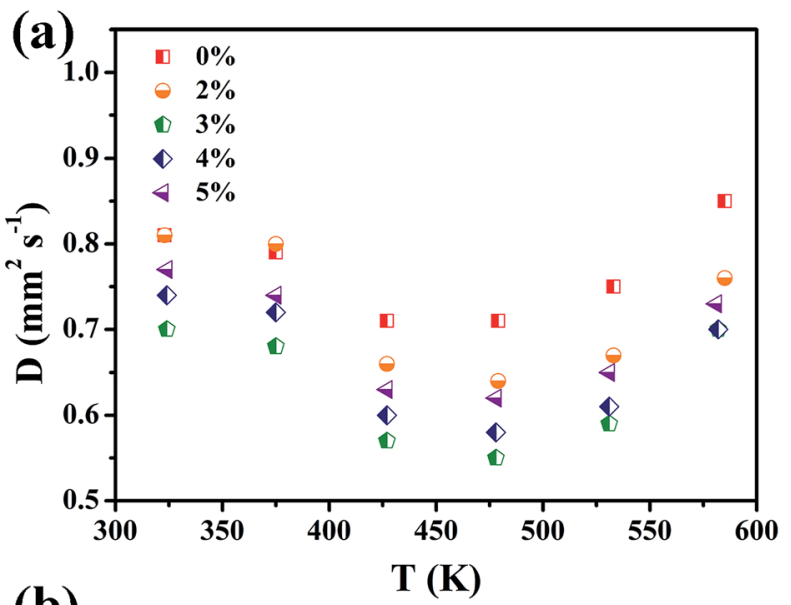

(b)

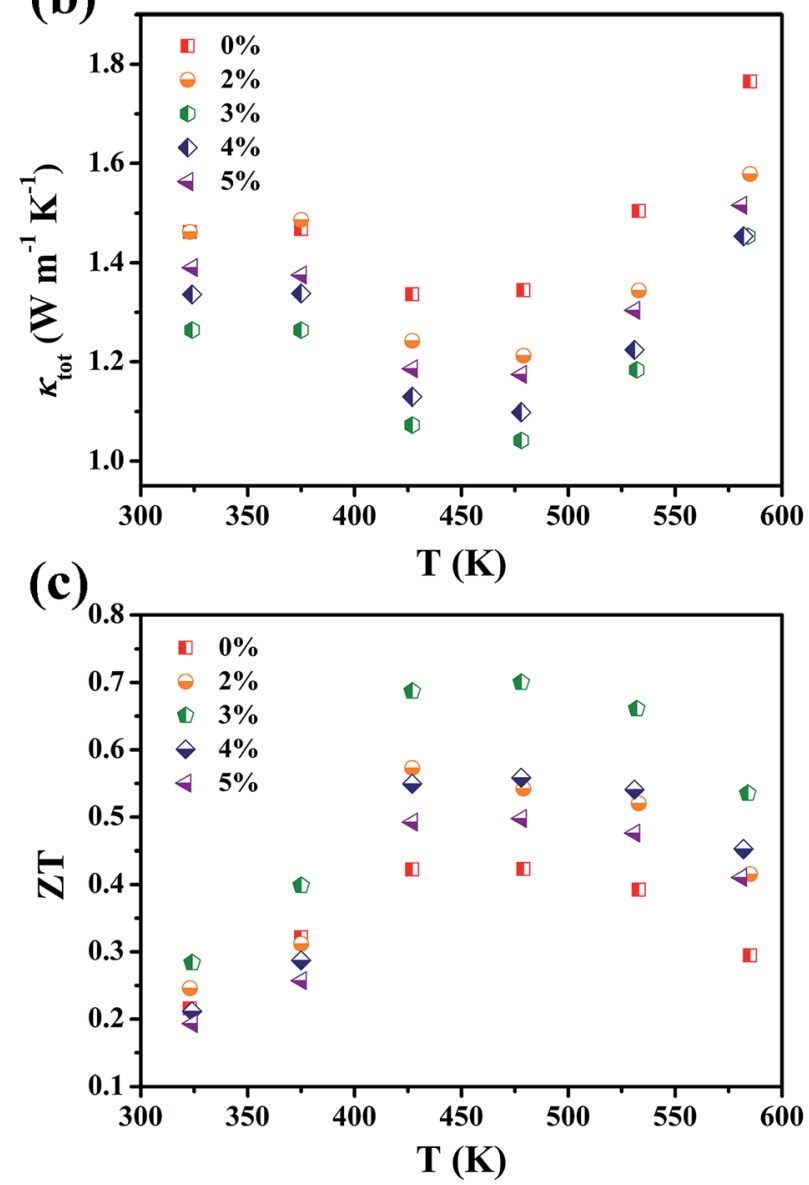

Fig. 5 Temperature-dependent (a) diffusivity coefficient; (b) thermal conductivity and (c) $Z T$ values for $\mathrm{Mg}_{1-x} \mathrm{Zn}_{x} \mathrm{Ag}_{0.9} \mathrm{Sb}_{0.95}(x=0-5 \%)$, respectively.

phenomenon might be ascribed to the bipolar effect, ${ }^{33,41}$ which is consistent with total thermal conductivity curves. Compared with the $Z T$ value of 0.42 at $473 \mathrm{~K}$ for $\mathrm{MgAg}_{0.9} \mathrm{Sb}_{0.95}$, the $Z T$ value of $\mathrm{Mg}_{0.97} \mathrm{Zn}_{0.03} \mathrm{Ag}_{0.9} \mathrm{Sb}_{0.95}$ increases by around $40 \%$.

\section{Conclusion}

We combined the ordinary planetary ball-milling and spark plasma sintering to synthesize MgAgSb-based alloys and improve their thermoelectric performance. On one hand, $\mathrm{Zn}$ substituted $\mathrm{Mg}$ in $\mathrm{Mg}_{1-x} \mathrm{Zn}_{x} \mathrm{Ag}_{0.9} \mathrm{Sb}_{0.95}(x=2-5 \%)$ enhances the purity and crystallinity, which possibly contribute to the reduction of the vacancy formation. This substitution could improve electrical performance of the sample to a certain extent. On the other hand, the benefits of combining ionized impurity scattering and the grain boundaries scattering drastically suppress thermal conductivity. Therefore, a peak value of $Z T \sim 0.7$ is obtained at $473 \mathrm{~K}$ for $\mathrm{Mg}_{0.97} \mathrm{Zn}_{0.03} \mathrm{Ag}_{0.9} \mathrm{Sb}_{0.95}$ by simultaneously optimized electrical and thermal performance. Our research presents a simple and economical ordinary planetary ball-milling method instead of the high energy ball milling to fabricate MgAgSb alloys with enhanced thermoelectric properties. This method could be further extended to preparation of other thermoelectric materials.

\section{Conflicts of interest}

There are no conflicts to declare.

\section{Acknowledgements}

This study was supported by National Natural Science Foundation of China under Grant No. 51572049, 51562005, 51772056; Natural Science Foundation of Guangxi Province, China under Grant No. 2015GXNSFFA139002, 2016GXNSFBA380152; and Innovation Project of GUET Graduate Education under Grant No. 2018YJCX89.

\section{References}

1 C. Chang and L. D. Zhao, Mater. Today Phys., 2018, 4, 50-57.

2 J. P. Heremans, V. Jovovic, E. S. Toberer, A. Saramat, K. Kurosaki, A. Charoenphakdee, S. Yamanaka and G. J. Snyder, Science, 2008, 321, 554-557.

3 G. J. Snyder and E. S. Toberer, Nat. Mater., 2008, 7, 105-114. 4 J. Yang, L. Xi, W. Qiu, L. Wu, X. Shi, L. Chen, J. Yang, W. Zhang, C. Uher and D. J. Singh, npj Comput. Mater., 2016, 2, 15015.

5 Y. Pei, X. Shi, A. Lalonde, H. Wang, L. Chen and G. J. Snyder, Nat. Mater., 2011, 473, 66-69.

6 Y. Pei, A. D. Lalonde, N. A. Heinz, X. Shi, S. Iwanaga, H. Wang, L. Chen and G. J. Snyder, Adv. Mater., 2011, 23, 5674-5678.

7 C. Fu, T. Zhu, Y. Pei, H. Xie, H. Wang, G. J. Snyder, Y. Liu, Y. Liu and X. Zhao, Adv. Energy Mater., 2014, 4, 1400600.

8 W. Zhao, Z. Liu, P. Wei, Q. Zhang, W. Zhu, X. Su, X. Tang, J. Yang, Y. Liu, J. Shi, Y. Chao, S. Lin and Y. Pei, Nat. Nanotechnol., 2017, 12, 55-60.

9 W. Zhao, Z. Liu, Z. Sun, Q. Zhang, P. Wei, X. Mu, H. Zhou, C. Li, S. Ma, D. He, P. Ji, W. Zhu, X. Nie, X. Su, X. Tang, B. Shen, X. Dong, J. Yang, Y. Liu and J. Shi, Nat. Mater., 2017, 549, 247-251.

10 R. He, D. Kraemer, J. Mao, L. Zeng, Q. Jie, Y. Lan, C. Li, J. Shuai, H. S. Kim, Y. Liu, D. Broido, C. W. Chu, G. Chen and Z. Ren, Proc. Natl. Acad. Sci. U. S. A., 2016, 113, 1357613581. 
11 X. Zhou, Y. Yan, X. Lu, H. Zhu, X. Han, G. Chen and Z. Ren, Mater. Today, 2018, DOI: 10.1016/j.mattod.2018.03.039.

12 L. D. Zhao, S. H. Lo, Y. Zhang, H. Sun, G. Tan, C. Uher, C. Wolverton, V. P. Dravid and M. G. Kanatzidis, Nat. Mater., 2016, 508, 373-377.

13 W. Li, S. Lin, B. Ge, J. Yang, W. Zhang and Y. Pei, Adv. Sci., 2016, 3, 1600196.

14 L. Li, Y. Liu, J. Dai, A. Hong, M. Zeng, Z. Yan, J. Xu, D. Zhang, D. Shan, S. Liu, Z. Ren and J.-M. Liu, J. Mater. Chem. C, 2016, 4, 5806-5813.

15 C. Chang, M. H. Wu, D. S. He, Y. L. Pei, C. F. Wu, X. F. Wu, H. L. Yu, F. Y. Zhu, K. D. Wang, Y. Chen, L. Huang, J. F. Li, J. Q. He and L. D. Zhao, Science, 2018, 360, 778-782.

16 J. Li, X. Zhang, Z. Chen, S. Lin, W. Li, J. Shen, I. T. Witting, A. Faghaninia, Y. Chen, A. Jain, L. Chen, G. J. Snyder and Y. Pei, Joule, 2018, 2, 976-987.

17 R. Nunna, P. Qiu, M. Yin, H. Chen, R. Hanus, Q. Song, T. Zhang, M. Y. Chou, M. T. Agne and J. He, Energy Environ. Sci., 2017, 10, 1928-1935.

18 R. Deng, X. Su, S. Hao, Z. Zheng, M. Zhang, H. Xie, W. Liu, Y. Yan, C. Wolverton, C. Uher, M. G. Kanatzidis and X. Tang, Energy Environ. Sci., 2018, 11, 1520-1535.

19 Y. Pan, U. Aydemir, F. H. Sun, C. F. Wu, T. C. Chasapis, G. J. Snyder and J. F. Li, Adv. Sci., 2017, 4, 1700259.

20 H. S. Kim, W. Liu and Z. Ren, Energy Environ. Sci., 2017, 10, 69-85.

21 J. Shuai, B. Ge, J. Mao, S. Song, Y. Wang and Z. Ren, J. Am. Chem. Soc., 2018, 140, 1910-1915.

22 S. Anand, K. Xia, V. I. Hegde, U. Aydemir, V. Kocevski, T. Zhu, C. Wolverton and G. J. Snyder, Energy Environ. Sci., 2018, 11, 140-1488.

23 K. Xia, Y. Liu, S. Anand, G. J. Snyder, J. Xin, J. Yu, X. Zhao and T. Zhu, Adv. Funct. Mater., 2018, 28, 1705845.

24 C. Fu, S. Bai, Y. Liu, Y. Tang, L. Chen, X. Zhao and T. Zhu, Nat. Commun., 2015, 6, 8144.

25 J. Yu, C. Fu, Y. Liu, K. Xia, U. Aydemir, T. C. Chasapis, G. J. Snyder, X. Zhao and T. Zhu, Adv. Energy Mater., 2018, 8, 1701313.

26 G. Joshi, R. He, M. Engber, G. Samsonidze, T. Pantha, E. Dahal, K. Dahal, J. Yang, Y. Lan, B. Kozinsky and Z. Ren, Energy Environ. Sci., 2014, 7, 4070-4076.

27 L. Huang, Y. Wang, J. Shuai, H. Zhang, S. Yang, Q. Zhang and Z. Ren, RSC Adv., 2015, 5, 102469-102476.

28 J.-L. Chen, C. Liu, L. Miao, J. Gao, Y.-y. Zheng, X. Wang, J. Lu and M. Shu, J. Electron. Mater., 2017, 47, 3248-3253.
29 H. Zhao, B. Cao, S. Li, N. Liu, J. Shen, S. Li, J. Jian, L. Gu, Y. Pei, G. J. Snyder, Z. Ren and X. Chen, Adv. Energy Mater., 2017, 7, 1700446.

30 Z. Liu, J. Mao, J. Sui and Z. Ren, Energy Environ. Sci., 2018, 11, 23-44.

31 X. Tan, L. Wang, H. Shao, S. Yue, J. Xu, G. Liu, H. Jiang and J. Jiang, Adv. Energy Mater., 2017, 7, 1700076.

32 M. J. Kirkham, A. M. dos Santos, C. J. Rawn, E. Lara-Curzio, J. W. Sharp and A. J. Thompson, Phys. Rev. B: Condens. Matter Mater. Phys., 2012, 85, 4506.

33 H. Zhao, J. Sui, Z. Tang, Y. Lan, Q. Jie, D. Kraemer, K. McEnaney, A. Guloy, G. Chen and Z. Ren, Nano Energy, 2014, 7, 97-103.

34 P. Ying, X. Liu, C. Fu, X. Yue, H. Xie, X. Zhao, W. Zhang and T. Zhu, Chem. Mater., 2015, 27, 909-913.

35 B. Poudel, Q. Hao, Y. Ma, Y. Lan, A. Minnich, B. Yu, X. Yan, D. Wang, A. Muto, D. Vashaee, X. Chen, J. Liu, M. S. Dresselhaus, G. Chen and Z. Ren, Science, 2008, 2, 634-638.

36 Z. Wang, T. Akao, T. Onda and Z. Chen, Scr. Mater., 2017, 136, 111-114.

37 T. Zhu, Z. Xu, J. He, J. Shen, S. Zhu, L. Hu, T. M. Tritt and X. Zhao, J. Mater. Chem. A, 2013, 1, 11589.

38 J. Lei, D. Zhang, W. Guan, Z. Cheng, C. Wang and Y. Wang, Phys. Chem. Chem. Phys., 2018, 20, 16729-16735.

39 B. Cordero, V. Gomez, A. E. Platero-Prats, M. Reves, J. Echeverria, E. Cremades, F. Barragan and S. Alvarez, Dalton Trans., 2008, 21, 2832-2838.

40 J. Mi, P. Ying, M. Sist, H. Reardon, P. Zhang, T. Zhu, X. Zhao and B. B. Iversen, Chem. Mater., 2017, 29, 6378-6388.

41 Z. Liu, Y. Wang, J. Mao, H. Geng, J. Shuai, Y. Wang, R. He, W. Cai, J. Sui and Z. Ren, Adv. Energy Mater., 2016, 6, 1502269.

42 S. Wang, J. Yang, L. Wu, P. Wei, W. Zhang and J. Yang, Adv. Funct. Mater., 2015, 25, 6660-6670.

43 T. Zhu, Y. Liu, C. Fu, J. P. Heremans, J. G. Snyder and X. Zhao, Adv. Mater., 2017, 29, 1605884.

44 J. Mao, J. Shuai, S. Song, Y. Wu, R. Dally, J. Zhou, Z. Liu, J. Sun, Q. Zhang, C. Dela Cruz, S. Wilson, Y. Pei, D. J. Singh, G. Chen, C. W. Chu and Z. Ren, Proc. Natl. Acad. Sci. U. S. A., 2017, 114, 10548-10553.

45 Y. Lan, A. J. Minnich, G. Chen and Z. Ren, Adv. Funct. Mater., 2010, 20, 357-376.

46 D. L. Medlin and G. J. Snyder, Curr. Opin. Colloid Interface Sci., 2009, 14, 226-235. 